\title{
ESTUDIO EVOLUTIVO DE LA INVESTIGACIÓN ESPAÑOLA CON CÉLULAS MADRE. VISUALIZACIÓN E IDENTIFICACIÓN DE LAS PRINCIPALES LÍNEAS DE INVESTIGACIÓN
}

\author{
Gisela Cantos-Mateos, María-Ángeles Zulueta, Benjamín Vargas-Quesada y \\ Zaida Chinchilla-Rodríguez
}

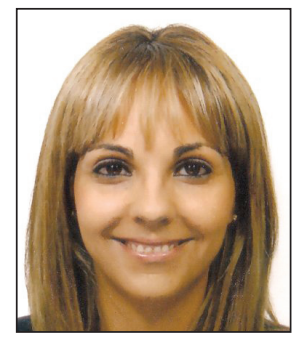

Gisela Cantos-Mateos es licenciada en historia y en documentación y máster en documentación. Becaria predoctoral (programa JAE-Predoc) del Instituto de Políticas y Bienes Públicos (IPP) del Consejo Superior de Investigaciones Científicas (CSIC). Realiza su tesis doctoral relacionada con análisis bibliométricos y con la representación y visualización de la información científica. Colabora con el Grupo SCImago.

http://orcid.org/0000-0003-2690-1790

Consejo Superior de Investigaciones Científicas. Instituto de Políticas y Bienes Públicos (CSIC-IPP) Albasanz, 26-28. 28037 Madrid, España gisela.cantos@csic.es

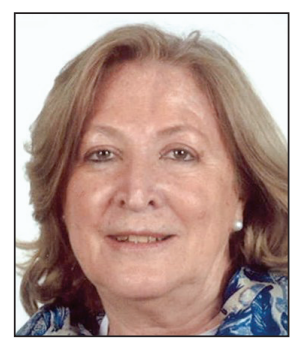

María-Ángeles Zulueta es licenciada en medicina y doctora en ciencias por la Universidad Autónoma de Madrid. Profesora titular del Departamento de Filología, Comunicación y Documentación de la Universidad de Alcalá e investigadora del Grupo SCImago. Sus áreas de investigación de interés se enmarcan en el campo de la bibliometría y análisis de dominios científicos. Ha dirigido y colaborado en varios proyectos de investigación financiados con fondos públicos en esta área y es autora de numerosas publicaciones en este campo.

http://orcid.org/0000-0002-3983-258X

Universidad de Alcalá. Facultad de Documentación San Cirilo, s/n. 28804, Alcalá de Henares, Madrid, España ma.zulueta@uah.es

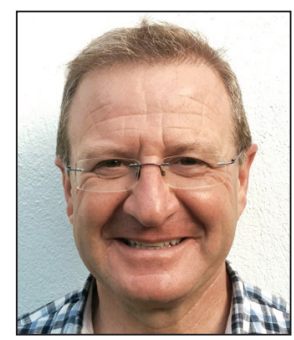

Benjamín Vargas-Quesada es profesor de técnicas avanzadas de recuperación de información en la Facultad de Comunicación y Documentación de la Universidad de Granada y miembro del Grupo SCImago. Sus líneas de investigación se centran en la visualización de la información científica y en la evaluación de la ciencia y de la comunicación científica. http://orcid.org/0000-0001-5115-7460

Universidad de Granada. Facultad de Comunicación y Documentación Colegio Máximo de Cartuja, s/n. 18071, Granada, España benjamin@ugr.es

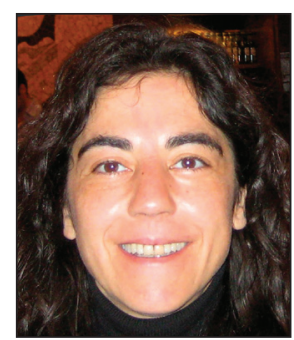

Zaida Chinchilla-Rodríguez es doctora en documentación e información científica y científica titular del Consejo Superior de Investigaciones Científicas (CSIC), en el Instituto de Políticas y Bienes Públicos (IPP) de Madrid. Miembro del Grupo SCImago, desarrolla su investigación en el análisis cienciométrico, la representación y visualización de información, redes de colaboración científica y propuestas metodológicas para el diseño de sistemas de información científica.

http://orcid.org/0000-0002-1608-4478

Consejo Superior de Investigaciones Científicas. Instituto de Políticas y Bienes Públicos (CSIC-IPP) Albasanz, 26-28. 28037 Madrid, España zaida.chinchilla@csic.es

\section{Resumen}

Se analiza la investigación española en células madre en el Science Citation Index (SCI) entre 1997 y 2010 con una división temporal en tres sub-períodos, mediante técnicas de visualización basadas en redes sociales. Se han utilizado los descriptores KeyWords Plus (KW+) como unidad de análisis, su coocurrencia como unidad de medida, y Pajek y VOSviewer como herramientas para la generación y visualización de redes sociales. Los resultados muestran dos imágenes complementarias de la investigación: la estructura estática, donde se distingue investigación clínica y básica, y la dinámica del análisis evolutivo, mostrando las líneas más consolidadas y las emergentes. Se plantea una propuesta metodológica para la visualización y detección de las principales líneas de investigación a lo largo del tiempo, su aplicabilidad y capacidad de predicción en dominios científicos y geográficos. 


\section{Palabras clave}

Análisis de co-words, Visualización de la información, Análisis de redes, Células madre, Tendencias de investigación, Evolución de la ciencia, España.

Title: Development of Spanish research on stem cells. Visualization and identification of the main research fronts

\section{Abstract}

Using visualization techniques based on social networks, this study aims to analyze stem cell research in Spain, as reflected in the Science Citation Index (SCI) database between 1997 and 2010, divided into three sub-periods. The selected unit of analysis was the KeyWords Plus descriptors $(K W+)$, the unit of measurement was their co-occurrence, and the Pajek and VOSviewer tools were used to generate and display the social networks. The results show two complementary images of research: the static structure, distinguishing between clinical and basic research, and the evolutionary dynamic, analysing both the most established and the emerging lines. The main contribution of this work is to present a methodology for the visualization and detection of the main research lines over time, demonstrating its applicability and its predictability in scientific and geographic domains.

\section{Keywords}

Co-word analysis, Network analysis, Information visualization, Stem cells, Science trends, Research trends, Spain.

Cantos-Mateos, Gisela; Zulueta, María-Ángeles; Vargas-Quesada, Benjamín; Chinchilla-Rodríguez, Zaida (2014). “Estudio evolutivo de la investigación española con células madre. Visualización e identificación de las principales líneas de investigación". El profesional de la información, mayo-junio, v. 23, n. 3, pp. 259-271.

http://dx.doi.org/10.3145/epi.2014.may.06

\section{Introducción}

Los estudios con células madre son una de las áreas de investigación que más ha evolucionado. Desde que en 1949 el científico John Hammond (1949) descubriese el método para mantener los embriones de ratón en cultivo in vitro, el progreso en este campo ha ido en aumento, ofreciendo perspectivas muy esperanzadoras en las últimas décadas para el tratamiento de enfermedades que hasta ahora parecían incurables. La investigación en este campo está teniendo grandes repercusiones científicas y sociales, desde los experimentos como la conocida clonación de la oveja Dolly (Wilmut et al., 1997) que tuvieron un especial impacto en el campo de la transferencia nuclear y la diferenciación y expresión celular en 1997, hasta la aparición entre 2006 y 2007 de las células de Yamanaka (Takahashi; Yamanaka, 2006; Takahashi et al., 2007) que ofrecen una alternativa mediante la posibilidad de obtener células pluripotentes a partir de la reprogramación de células adultas. Al mismo tiempo se ha generado un importante debate bioético que afecta a la regulación legislativa y la financiación de la investigación con células madre embrionarias, reglamentando así su desarrollo.

Aunque es difícil establecer una relación directa entre las reformas legislativas y la evolución de la investigación, los hitos científicos podrían estar influenciados por las regulaciones legislativas. Pese a las controversias que suscita el desarrollo de determinadas líneas de investigación con células madre, en los últimos años ha habido iniciativas políticas, económicas y legislativas que manifiestan una clara intención de adecuar los hitos científicos a las estructuras sociales de nuestro tiempo. En Europa se pueden destacar importantes esfuerzos para el impulso de la investigación mediante medidas legislativas adoptadas desde 2001: la in- centivación económica a través del VII Programa marco y la creación del Registro europeo de células madre embrionarias con el objetivo de proporcionar información a toda la comunidad científica, sobre las líneas de células disponibles en Europa. España ha ido modificando su legislación adoptando las directivas europeas hasta 2006. Estados Unidos, Reino Unido, Australia y Asia han ido legislando al respecto, y a lo largo de los años las regulaciones han sido sometidas a una continua revisión (EuroStemCell et al., 2013). En cualquier caso, las normativas y la financiación de proyectos de investigación con células madre podrían afectar a los resultados de la producción científica tanto a nivel internacional como nacional. Aunque no es el objeto de este estudio, parece adecuado plantear el marco en el que se desarrolla este campo científico.

La idea es presentar un análisis aplicable no sólo a la investigación española con células madre, sino a otros dominios temáticos, geográficos y temporales

Todos estos hitos han contribuido a generar importantes resultados de esta actividad científica, susceptibles de ser analizados desde la perspectiva bibliométrica, especialmente porque esta investigación con células madre ha trascendido a otros campos científicos, siendo un tema con un importante carácter multidisciplinar. Por ello es un reto definir temáticamente el dominio y las principales líneas de investigación en las que se está trabajando.

Los estudios bibliométricos ayudan en esta tarea ya que el estudio de nuevas técnicas y herramientas ha mejorado 
notablemente la comprensión y análisis de dominios científicos (Leydesdorff; Rafols, 2009; Vargas-Quesada et al., 2010; Rafols; Porter; Leydesdorff, 2010; Boyack; Börner; Klavans, 2009), y especialmente en el campo de la visualización de la información (Börner; Chen; Boyack, 2003; DeMoya-Anegón et al., 2006; Vargas-Quesada et al., 2008). La incorporación del análisis estructural de redes sociales (Wasserman; Faust, 1998) lo ha convertido en una herramienta fundamental para visualizar y analizar las relaciones estructurales que se producen en un contexto científico determinado. En el caso de la delimitación temática ayuda a visualizar la interacción de los aspectos más destacados en el dominio, haciendo posible la identificación de áreas o líneas de investigación.

\section{La obtención de los descriptores} KeyWords Plus no requiere de minería textual ni de ningún pre-procesamiento lingüístico

Existe gran diversidad de métodos y técnicas a la hora de delimitar y visualizar un campo científico. Hay estudios que utilizan la cocitación de autores (author co-citation analysis o ACA) (White; Griffith, 1981; White; McCain, 1998; Small; Upham, 2009; Chen; Ibekwe-SanJuan; Hou, 2010; Zhao; Strotmann, 2011), el análisis de emparejamiento bibliográfico (bibliographic coupling) (Kessler, 1963; Boyack; Klavans, 2010; Chen et al., 2011; Glänzel; Thijs, 2011), estudios de co-words (Callon et al., 1983; Rip; Courtial, 1984, Cambrosio et al., 1993; Van-Raan; Tijssen, 1993; Ding; Chowdhurry; Foo, 2001; Lee, 2008; Leydesdorff; Welbers, 2011; Zulueta et al., 2011; Cantos-Mateos et al., 2013; RomoFernández; Guerrero-Bote; De-Moya-Anegón, 2013) o los estudios híbridos en los que se combinan tanto ACA como co-words (Zitt; Bassecoulard, 1996; Zitt; Lelu; Bassecoulard, 2011).

En vista de las ventajas e inconvenientes que condicionan la elección de una metodología sobre otra, para el presente estudio se ha optado por el análisis de co-words (Zitt; Lelu; Bassecoulard, 2011). Según Michel Zitt y colaboradores (2011), las palabras, a diferencia de las citas, parecen adaptarse mejor a la "ciencia viva" porque son universales. Además las citas podría considerarse que aluden a temas menos actuales, ya que conforman el trasfondo del documento, mientras que las palabras son coetáneas al propio documento (Soos; Kampis; Gulyás, 2013). Para estos autores las unidades lingüísticas tienen la capacidad de reflejar mejor la incidencia de los contextos científicos, sociales y políticos, propios de los dominios más controvertidos y áreas emergentes.

Se puede apreciar con mayor claridad la dinámica del campo si se aplica una perspectiva temporal. Este tipo de análisis permite detectar la evolución de los principales temas de investigación a lo largo del tiempo (Braam; Moed; Van-Raan, 1991; Gábor, 2006; Leydesdorff; Schank, 2008; Boyack; Börner; Klavans, 2009; Chen; Ibekwe-SanJuan; Hou, 2010; Soos; Kampis; Gulyás, 2013). En este caso las visualizacio- nes de redes de co-words de distintos sub-períodos permiten localizar qué temas persisten, desaparecen o emergen en el campo (Braam; Moed; Van-Raan, 1991).

A partir de este marco, los objetivos de este estudio son de carácter fundamentalmente metodológicos. La idea es presentar un análisis que sea aplicable no sólo a la investigación española con células madre, sino a otros dominios temáticos, geográficos y temporales, distintos al que se aborda en este trabajo. Por tanto la presente propuesta metodológica pretende por un lado identificar las principales líneas de investigación a partir de la localización y visualización de la estructura temática del dominio. Y por otro lado reflejar la dinámica del campo a través de la evolución que experimentan las principales líneas de investigación a lo largo del período de estudio. Todo ello a través de la visualización de redes de co-words ${ }^{1}$.

\section{Material y métodos}

\subsection{Fuente de información}

Los documentos de este estudio proceden de la base de datos Science Citation Index ( $\mathrm{SCl}$ ). La estrategia de búsqueda empleada consistió en utilizar los términos stem* cell* en el campo Topic, Spain en el campo Address y limitada al período temporal de 1997-2010. Se recuperó un total de 4.148 documentos.

\subsection{Unidades de análisis}

Se han seleccionado los descriptores KeyWords Plus $(K W+)^{2}$ como unidades de análisis. Se trata de un vocabulario automatizado que utiliza el SCl para indizar los documentos, que se obtiene mediante un algoritmo de búsqueda que extrae las palabras clave de los títulos de las referencias contenidas en los documentos (Garfield, 1990; Garfield; Sher, 1993). En la investigación con células madre estos descriptores tienen una elevada representatividad (78,25\% de los documentos) en comparación con los Author keywords ${ }^{3}$ (52,96\%), como ha quedado de manifiesto en trabajos anteriores (CantosMateos et al., 2013).

\section{El uso de descriptores KeyWords Plus permite realizar un análisis temático de granularidad fina y contiene terminolo- gía más actualizada y específica, en com- paración con otros descriptores}

El uso de estos descriptores tiene la ventaja de que su obtención no requiere de minería textual ni de ningún pre-procesamiento lingüístico. Permite además realizar un análisis temático de granularidad más fina que otro tipo de unidades como pueden ser las categorías, ya que aluden directamente al contenido conceptual de los documentos (Soos; Kampis; Gulyás, 2013). Por otro lado, al tratarse de términos procedentes de los títulos de los artículos que aparecen en las referencias, son los propios autores quienes seleccionan y comunican cuáles son los términos esenciales para expresar el contenido más importante de sus trabajos de investigación. Esta característica favorece la aparición de una 


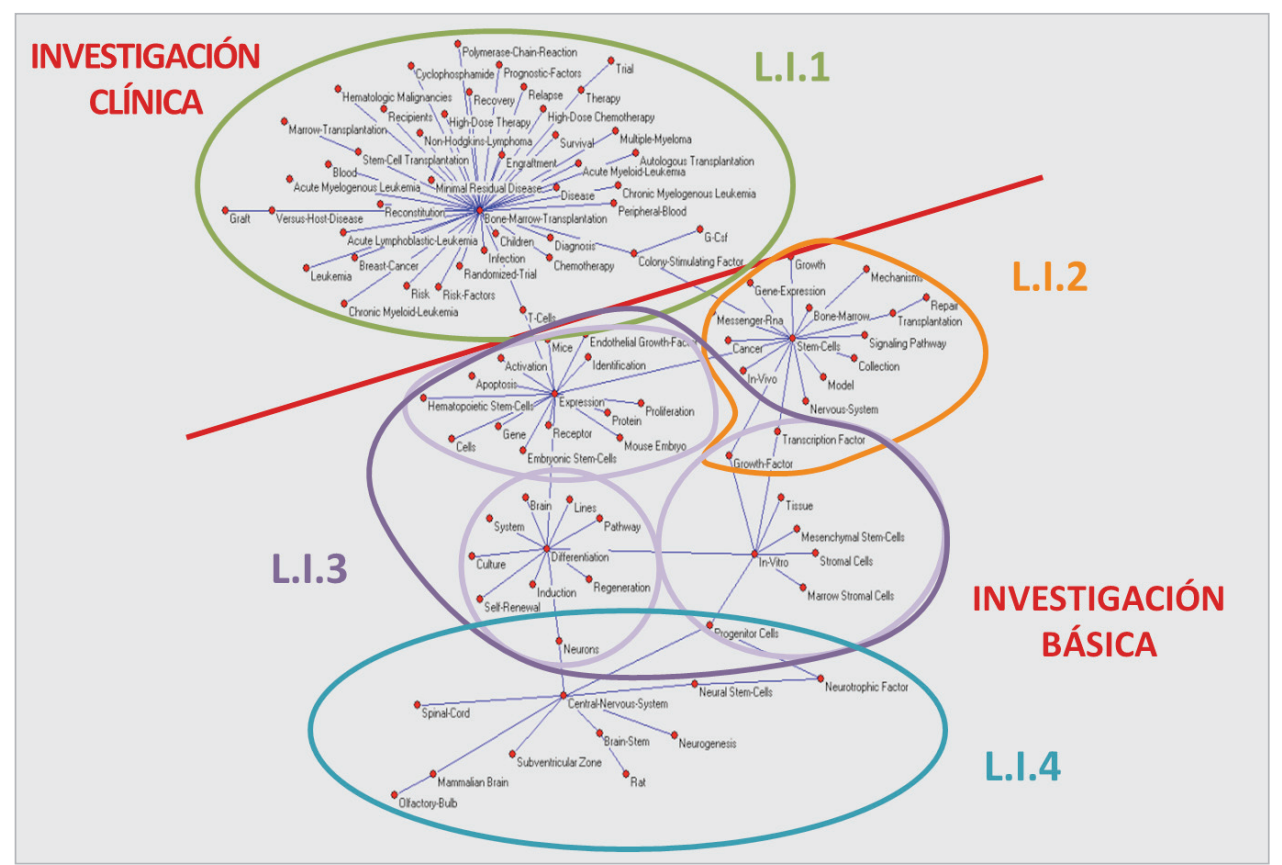

Figura 1. Período completo (1997-2010). Representación en Pajek de los 99 KW+ más frecuentes. resultado es una matriz de co-ocurrencias que refleja el número de veces que un par de descriptores aparecen conjuntamente en dos documentos.

Para el estudio evolutivo se ha analizado el período completo en su conjunto (1997-2010), y subdivido en otros tres períodos, como muestra la tabla 1. La segmentación temporal ha sido establecida considerando dos criterios complementarios.

El primero son los principales hitos científicos. Partiendo de 1997, cuando tuvieron lugar los exitosos ensayos del Roslin Institute de Edimburgo, se desencaterminología más actualizada y específica en comparación con otros tipos de descriptores, como son los procedentes de un vocabulario controlado (Braam; Moed; Van-Raan, 1991). Como demuestran estudios recientes, estas cualidades contribuyen a reflejar mejor los aspectos temáticos más dinámicos de un dominio.

Los $K W+$ tienen la desventaja sin embargo de presentar una amplia dispersión terminológica debida a la falta de normalización. Este aspecto hay que resaltarlo como una de las posibles limitaciones de este trabajo. Para paliarla en cierto modo se ha realizado una normalización moderada en la que se han tratado de unificar criterios gramaticales (plurales y singulares) y ortográficos (guiones, mayúsculas y minúsculas).

\subsection{Unidades de medida y análisis temporal}

El análisis bibliométrico para la detección y visualización de las principales líneas de investigación y su evolución a lo largo del tiempo, ha consistido en calcular las relaciones que se producen entre los $K W+$ a partir de su aparición conjunta en los documentos, lo que se conoce como co-words analysis. Dicho análisis consiste en generar una matriz cuadrada de $\mathrm{NxN}$ elementos, donde $\mathrm{N}$ es el descriptor $K W+$ a representar, a partir de las veces que ocurre en los documentos. EI

Tabla 1. Períodos temporales analizados

\begin{tabular}{|l|c|}
\hline \multicolumn{1}{|c|}{ Períodos } & Años \\
\hline Período completo & $1997-2010$ \\
\hline Primer período & $1997-2001$ \\
\hline Segundo período & $2002-2006$ \\
\hline Tercer período & $2007-2010$ \\
\hline
\end{tabular}

denó un tiempo de incertidumbre en la regulación legislativa y las políticas de financiación pública que condicionaron el avance de la investigación en células madre embrionarias. El proceso comenzó a normalizarse fundamentalmente entre los años 2002 y 2006. A partir de 2007 esta investigación recibió un importante impulso gracias al descubrimiento de las células madre de pluripotencia inducida (células iPS) a partir de células humanas adultas que planteaban una alternativa a los problemas éticos-jurídicos sobre la obtención de células madre embrionarias obtenidas a partir de la masa celular interna de un embrión, lo que suponía la destrucción del mismo (EuroStemCell et al., 2013).

El segundo criterio ha sido que el volumen documental de cada período sea lo suficientemente representativo como para permitir la detección de líneas de investigación.

\subsection{Visualización de la información}

La visualización de las relaciones entre los $K W+$ se ha hecho siguiendo dos métodos en base al uso de dos programas especializados en visualización y análisis de grandes redes, que permiten obtener unas representaciones que favorecen la identificación de las principales líneas de investigación y su evolución.

Por un lado se ha empleado el programa Pajek (Batagelj; Mrvar, 2010). Se utilizó una matriz de co-ocurrencias de descriptores con datos en bruto en combinación con el algoritmo de poda Pathfinder (De-Moya-Anegón et al., 2007a, 2007b; Zulueta et al., 2011) para la reducción del espacio dimensional. Este algoritmo está basado en el principio de Éste ayuda a preservar y poner de relieve las relaciones más desigualdad del triángulo bajo los parámetros $r=\infty$ y $q=n-1$.

Tabla 2. Número de documentos por años

\begin{tabular}{|c|c|c|c|c|c|c|c|c|c|c|c|c|c|c|}
\hline Período & \multicolumn{5}{|c|}{ Primer período } & \multicolumn{5}{|c|}{ Segundo período } & \multicolumn{4}{|c|}{ Tercer período } \\
\hline Años & 1997 & 1998 & 1999 & 2000 & 2001 & 2002 & 2003 & 2004 & 2005 & 2006 & 2007 & 2008 & 2009 & 2010 \\
\hline No docs. & 94 & 142 & 176 & 149 & 163 & 167 & 165 & 296 & 271 & 351 & 395 & 494 & 608 & 677 \\
\hline Total docs. & \multicolumn{5}{|c|}{724} & \multicolumn{5}{|c|}{1.250} & \multicolumn{4}{|c|}{2.174} \\
\hline
\end{tabular}




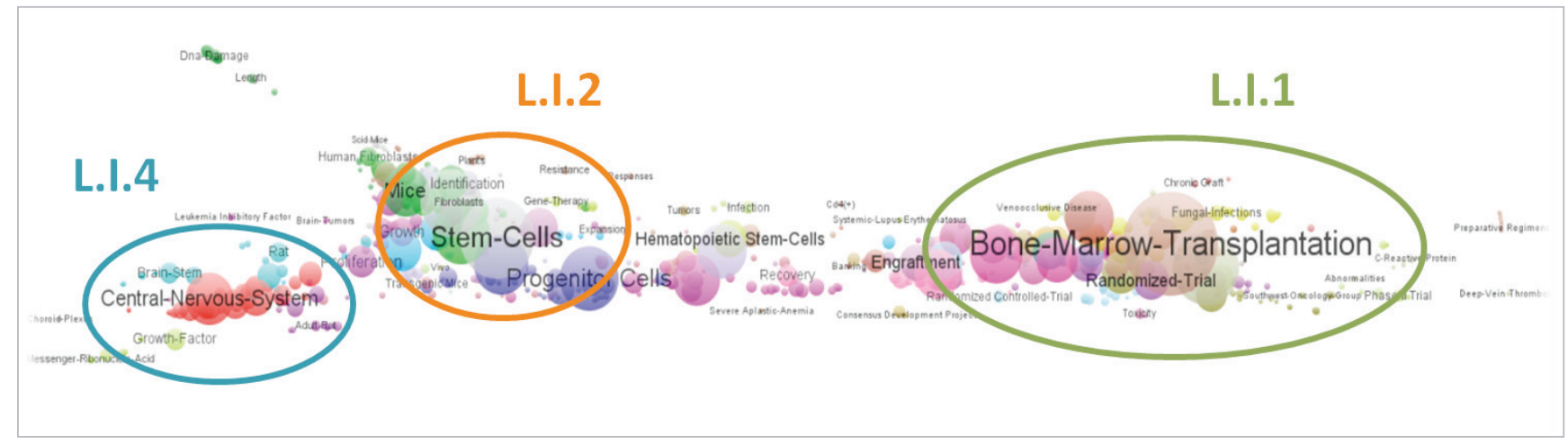

Figura 2. Período completo (1997-2010). Mapa de clusters representado con VOSviewer (número de nodos: 668).

destacadas entre los descriptores (White, 2003; Vargas-Quesada et al., 2008; De-Moya-Anegón et al., 2009). Como algoritmo de visualización se utilizó Kamada-Kawai (Kamada; Kawai, 1989) incluido en Pajek. Aunque este programa permite representar grandes redes, se decidió incorporar únicamente los descriptores más frecuentes. Tras varios ensayos donde se probaron distintos umbrales de frecuencias para la generación de los mapas, se observó que el mejor compromiso entre visualización y análisis, teniendo en cuenta que se trabaja con las limitaciones propias de la pantalla de un ordenador, es el de redes compuestas en torno a los 100 nodos (Zulueta et al., 2011).

Por otro lado se ha utilizado el programa VOSviewer v. 1.5.3 (Van-Eck; Waltman, 2010), que es una alternativa a las representaciones multidimensionales combinando técnicas de visualización y clustering. En este caso se ha construido una matriz de co-ocurrencia normalizada a través de la medida de similitud que utiliza VOSviewer, basada en la fuerza de asociación de los ítems. El umbral de dicha coocurrencia ha sido fijo para todas las representaciones. De los cuatro tipos de visualizaciones que ofrece, se han utilizado los mapas etiquetados con nombres, donde cada descriptor está representado por una etiqueta y cuyo tamaño es proporcional a su peso, junto con los denominados "mapas de calor" (o mapas de densidad). Estos últimos se caracterizan porque cada nodo en el mapa se representa con un color que va del rojo al azul, reflejando la densidad de las relaciones entre los descriptores. Cuanto mayor es la densidad, es decir la co-ocurrencia entre descriptores, más se aproximarán a la tonalidad roja; en cambio la mayor aproximación al azul indica una mayor dispersión y por lo tanto menos co-ocurrencia.

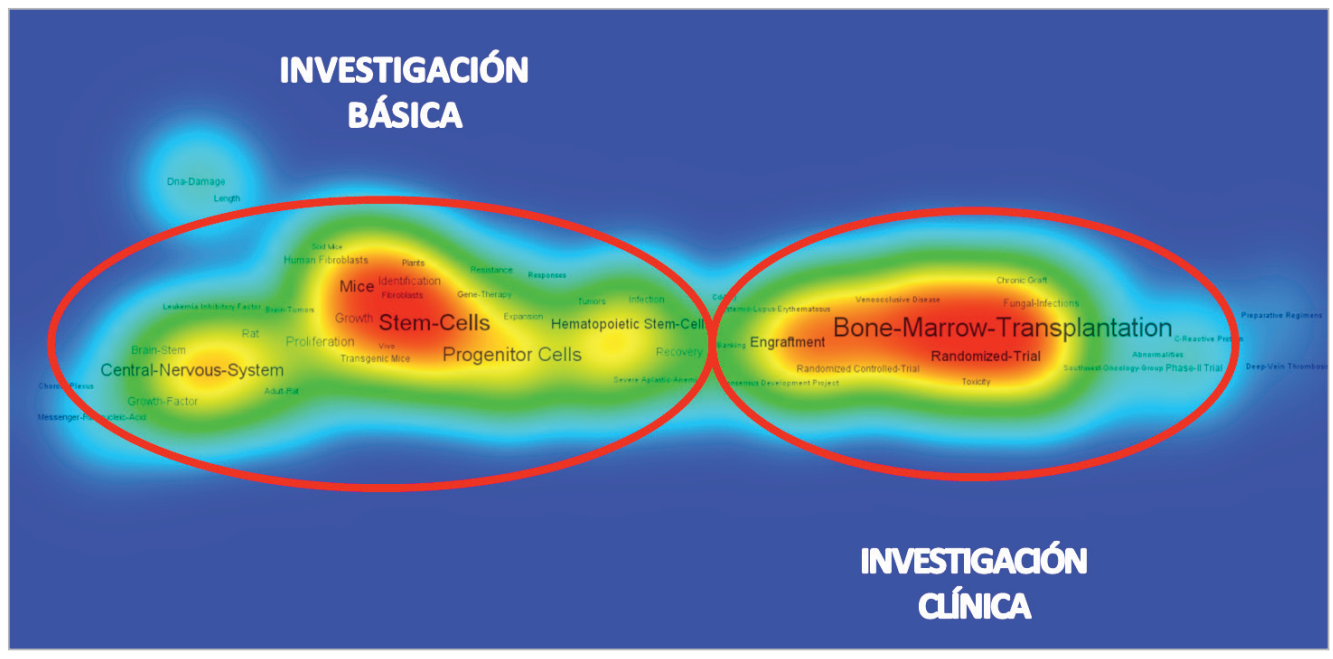

Figura 3. Período completo (1997-2010). Mapa de calor representado con VOSviewer.

\section{Resultados y discusión}

El número de documentos recuperados fue de 4.148 para el período 1997-2010. La tabla 2 muestra el volumen de producción por tramos temporales.

\subsection{Período temporal completo (1997-2010)}

De los 4.148 documentos recuperados para todo el período, el 78,25\% están indizados con $K W+$, contabilizándose 28.733 descriptores, de los cuales 9.465 son únicos (tabla 3 ).

En la figura 1 se aprecian hasta 6 agrupaciones de descriptores $K W+$ que, por su significado y relación con los demás, podemos considerar que definen líneas de investigación. Se distinguen estructuralmente dos naturalezas temáticas de la investigación claramente diferenciadas. Por un lado la investigación clínica representada por los descriptores agrupados bajo Bone-Marrow-Transplantation (figuras 1 y 3), relacionados con los estudios sobre el uso terapéutico de

\begin{tabular}{|c|c|c|c|}
\hline \multicolumn{4}{|c|}{ Período completo (1997-2010) } \\
\hline \multirow{2}{*}{ Documentos } & \multicolumn{2}{|l|}{ Totales } & 4.148 \\
\hline & \multicolumn{2}{|c|}{ Indizados con $K W+$} & $3.246(78,25 \%)$ \\
\hline \multirow{5}{*}{$K W_{+}$} & \multicolumn{2}{|l|}{ Totales } & 28.733 \\
\hline & \multirow{2}{*}{ Únicos } & Sin normalización & 9.833 \\
\hline & & Con normalización & 9.465 \\
\hline & \multicolumn{2}{|c|}{ Por documento } & 8,85 \\
\hline & \multicolumn{2}{|c|}{ Frecuencia media de aparición } & 3,04 \\
\hline
\end{tabular}


Tabla 4. Datos del primer período (1997-2001)

\begin{tabular}{|c|c|c|c|}
\hline \multicolumn{4}{|c|}{ Primer período (1997-2001) } \\
\hline \multirow{2}{*}{ Documentos } & \multicolumn{2}{|l|}{ Totales } & 724 \\
\hline & \multicolumn{2}{|c|}{ Indizados con $K W+$} & $560(77,35 \%)$ \\
\hline \multirow{5}{*}{$K W+$} & \multicolumn{2}{|c|}{ Totales } & 4.631 \\
\hline & \multirow{2}{*}{ Únicos } & Sin normalización & 2.134 \\
\hline & & Con normalización & 2.080 \\
\hline & \multicolumn{2}{|c|}{ Por documento } & 8,27 \\
\hline & \multicolumn{2}{|c|}{ Frecuencia media de aparición } & 2,23 \\
\hline
\end{tabular}

nen relación con las células madre embrionarias (L.I.3). Esta línea se encuentra desagregada en tres agrupaciones: procesos de expresión, diferenciación celular y procesos y biotecnologías necesarias para localizar, producir, crecer y analizar in-vitro las células madre embrionarias.

La última agrupación se relaciona con la investigación con células madre neurales (L.I.4). Estos descriptores están muy ligados con los estudios sobre desarrollo e identificación de las células

las células madre en enfermedades hematológicas (L.I.1). Por otro la investigación básica representada por el resto de agrupaciones.

En la investigación básica (figura 1) existen dos agrupaciones que conectan directamente con la clínica: los descriptores vinculados con Stem Cells, relacionados con los estudios sobre células madre hematopoyéticas (L.I.2) y los que tie-

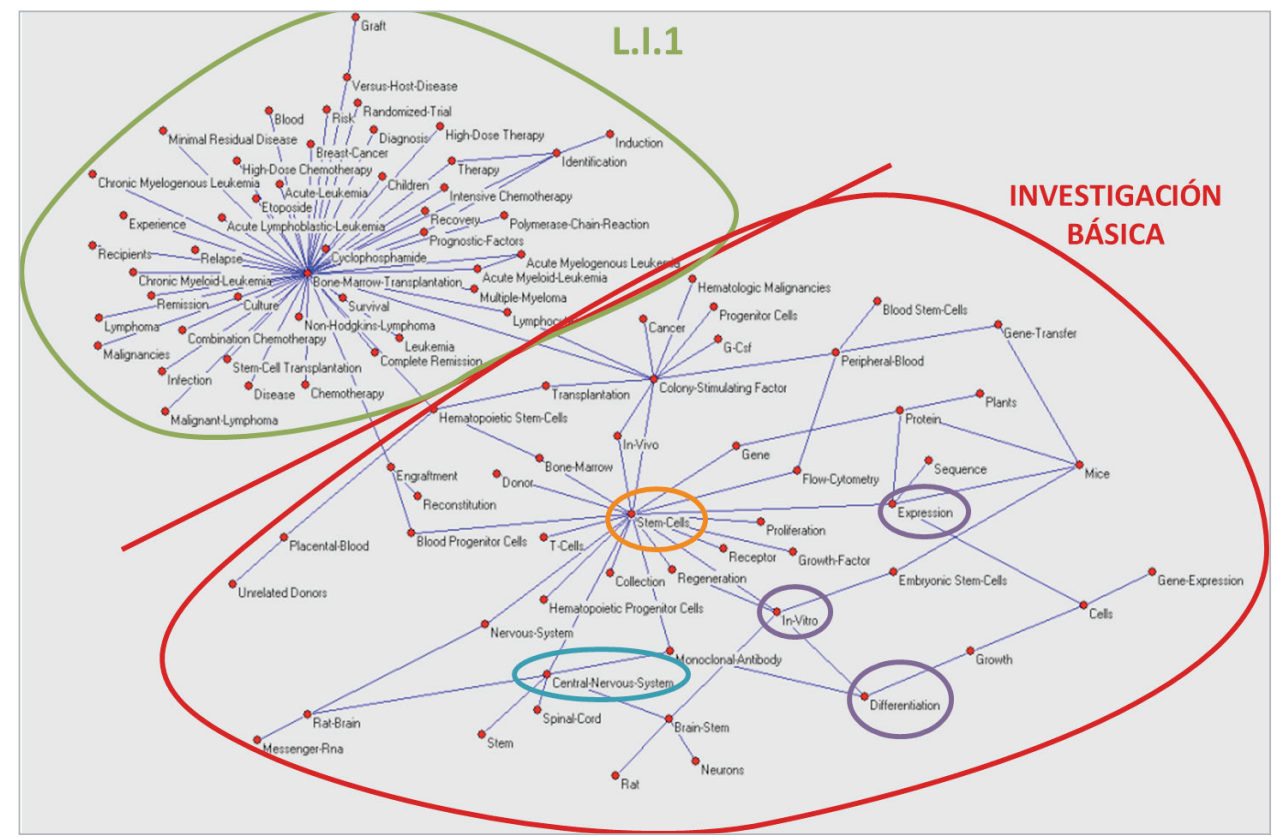
madre neuronales que se diferencian activamente en el tejido cerebral.

En la representación de VOSviewer (figura 2) no se identifica de una manera tan nítida el mismo número de agrupaciones. Sólo se identifican claramente 3 :

- agrupación del clúster marrón encabezada por el descriptor Bone-Marrow-Transplantation (L.I.1);

- la situada en la parte central bajo el descriptor Stem-Cells (L.I.2);

- la situada en la zona derecha, representada por el clúster de color rojo encabezada por el descriptor Central-NervousSystem (L.I.4).

El resto de los nodos aparecen muy entremezclados y son difícilmente detectables.

En las zonas con mayor densidad de la red (figura 3 ), se distinguen claramente dos zonas que concentran una importante actividad de relaciones, una de investigación básica y otra de clínica.

Figura 4. Primer período (1997-2001). Representación en Pajek de los 95 KW+ más frecuentes.

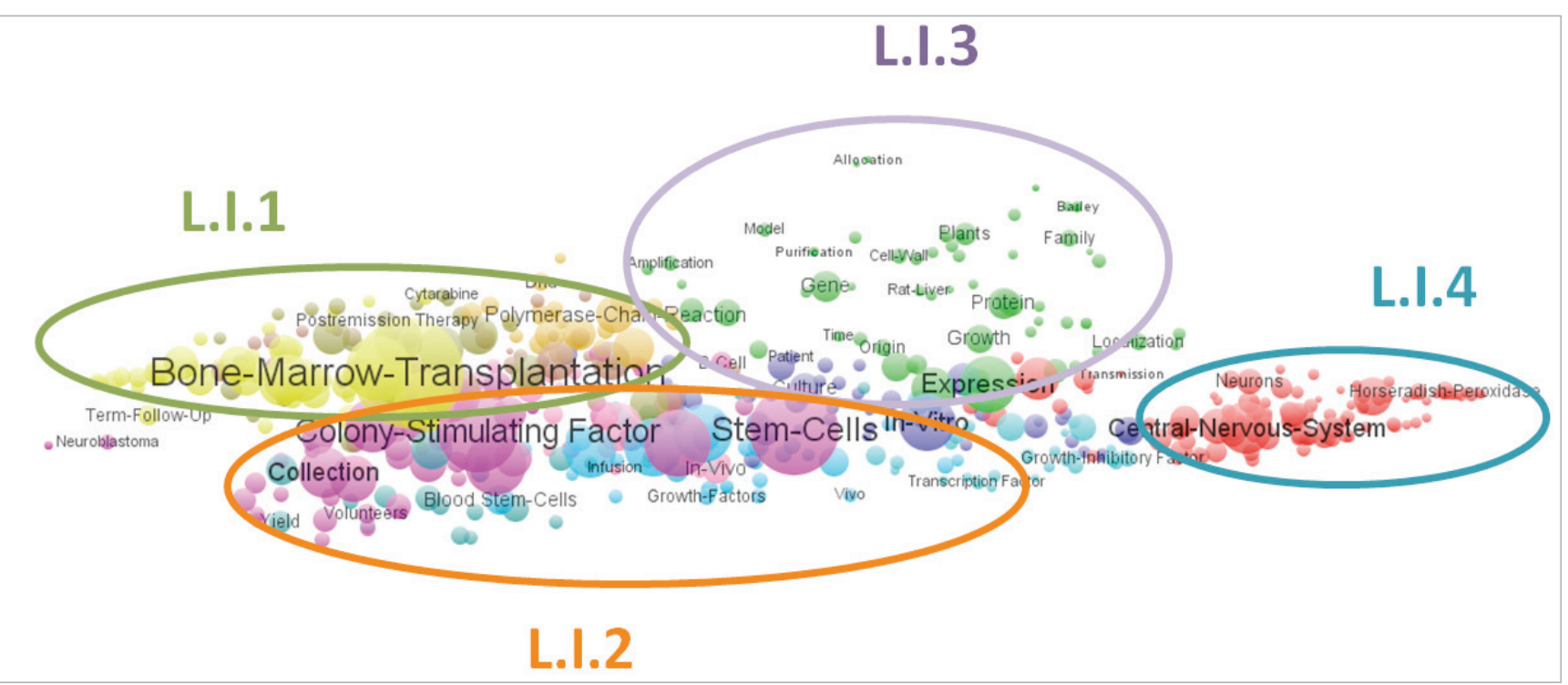

Figura 5. Primer período (1997-2001). Mapa de clusters representado con VOSviewer (número de nodos: 543) 


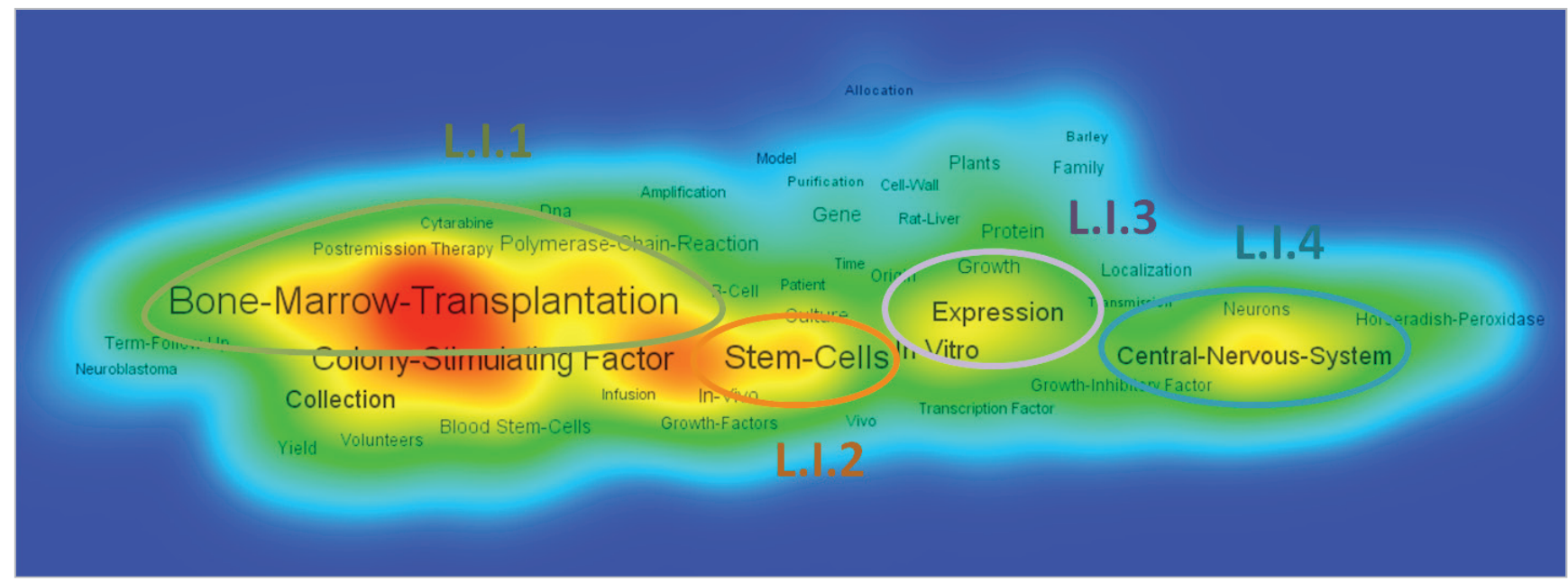

Figura 6. Primer período (1997-2001). Mapa de calor representado con VOSviewer.

\subsection{Primer período (1997-2001)}

El número de documentos es de 724 y el de descriptores de $2.080 \mathrm{KW}+$ únicos (tabla 4).

La visualización del dominio ha cambiado sustancialmente. A pesar de ello, la distinción entre la investigación clínica y la básica sigue siendo muy clara, incluso más, que con respecto al período completo.
Tabla 5. Datos del segundo período (2002-2006)

\begin{tabular}{|l|l|l|l|}
\hline \multicolumn{3}{|c|}{ Segundo período (2002-2006) } \\
\hline \multirow{3}{*}{ Documentos } & \multicolumn{2}{|l|}{ Totales } & 1.250 \\
\cline { 2 - 4 } & Indizados con KW+ & $979(78,32 \%)$ \\
\hline \multirow{4}{*}{$K W+$} & \multicolumn{2}{|l|}{ Totales } & 8.581 \\
\cline { 2 - 4 } & \multirow{3}{*}{ Únicos } & Sin normalización & 3.966 \\
\cline { 2 - 3 } & Con normalización & 3.852 \\
\cline { 2 - 3 } & Por documento & 8,76 \\
\cline { 2 - 3 } & Frecuencia media de aparición & 2,23 \\
\hline
\end{tabular}

En la figura 4 se aprecia un grupo muy numeroso de $K W+$ relacionados con la investigación clínica. La composición de los descriptores de esta línea (L.I.1) es muy similar a la que se ha descrito en el período completo. Su clara definición refleja que estos estudios están muy consolidados.

El resto de las líneas que integraban la investigación de carácter más básico (L.I.2, L.I.3 y L.I.4) no parecen estar tan definidas. Según la figura 4, es posible detectar la mayor parte de los descriptores presentes en el período completo, incluso los que ejercían mayor influencia dentro de cada línea de investigación. A pesar de ello, el comportamiento relacional entre ellos es distinto en este primer período. La mayoría de relaciones parten del descriptor Stem Cells, constituyendo el nodo principal. También se aprecia en la figura 5 , donde constituye uno de los cuatro clusters que mejor se diferencian en el mapa. De manera más específica y poco definida, se detectan dos agrupaciones que mantienen cierta identidad:

- procesos que intervienen en la proliferación de líneas celulares (figura 5 , clúster verde);

- relacionados con células madre neurales (figura 5, clúster rojo).

Lo mismo se puede localizar en el mapa de densidades de la figura 6. Estas débiles agrupaciones forman líneas de investigación emergentes, como se muestra en los siguientes períodos.

\subsection{Segundo período (2002-2006)}

El número de documentos asciende a 1.250. El número de $K W+$ únicos también se incrementa, hasta 3.852 descriptores.

Se mantiene la distinción entre investigación clínica y básica. En la figura 9 se aprecia que esos son los dos focos más importantes, aunque la densidad es mucho mayor en la investigación clínica.

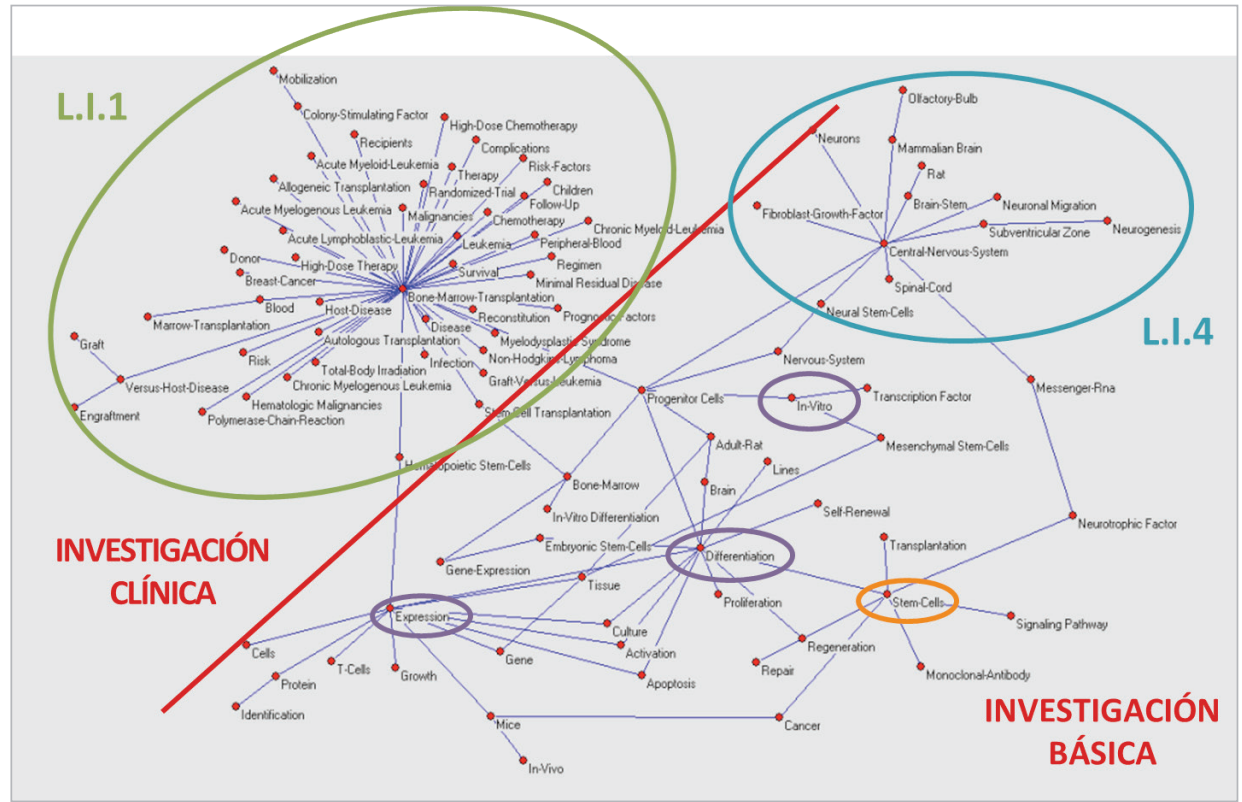

Figura 7. Segundo período (2002-2006). Representación en Pajek de los 96 KW+ más frecuentes. 


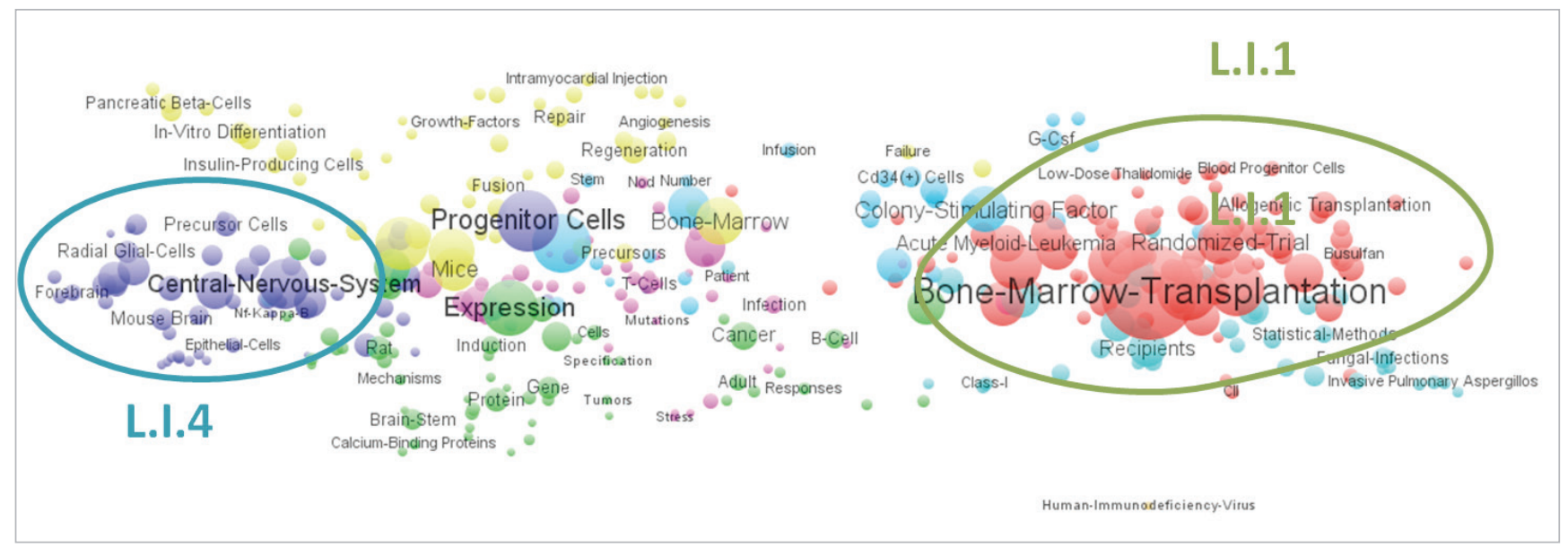

Figura 8. Segundo período (2002-2006). Mapa de clusters representado con VOSviewer (número de nodos: 363).

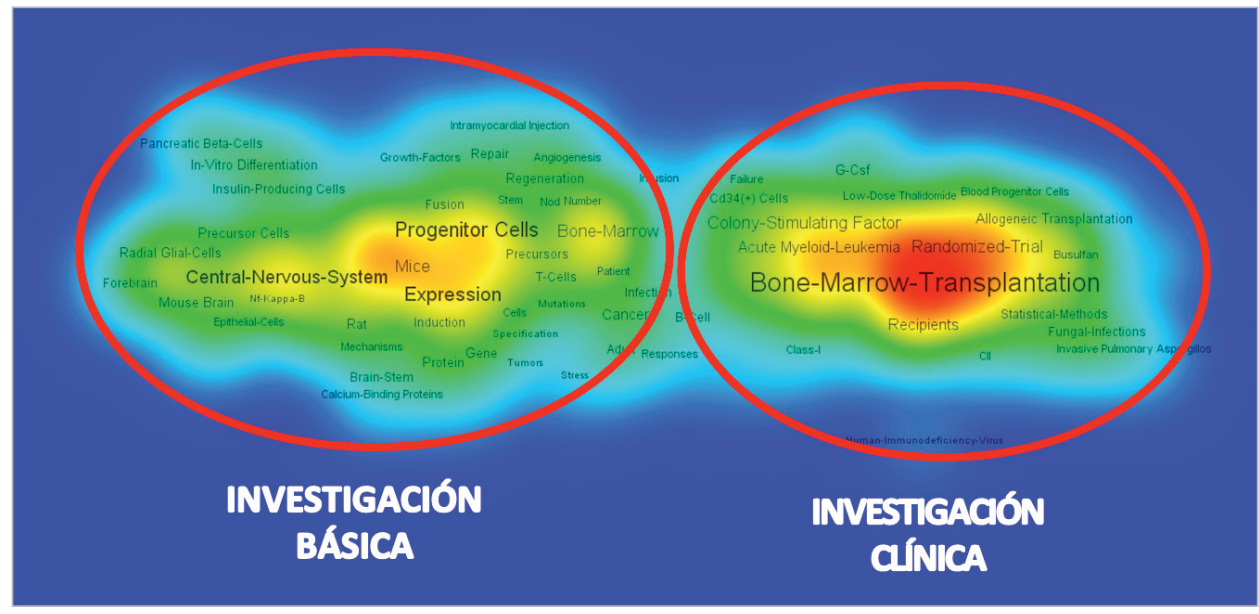

Figura 9. Segundo período (2002-2006). Mapa de calor representado con VOSviewer. de investigación durante este período.

\subsection{Tercer período (2007-2010)}

Es el período con mayor número de documentos (2.174) y descriptores $(6.178$ $K W+$ únicos).

Las visualizaciones permiten detectar cambios importantes en la evolución de la estructura y composición temática de las líneas de investigación. La distinción entre investigación clínica y básica sigue siendo clara (figura 12),

La agrupación más numerosa y definida (figura 7) es la del uso terapéutico de las células madre en enfermedades hematológicas (L.I.1). La presencia de esta línea confirma la consolidación de estos estudios para este período.

La investigación de carácter más básico se muestra estructuralmente mejor definida. Los estudios relacionados con las células madre hematopoyéticas (L.I.2) identificados mediante los descriptores conectados con Stem-Cells, ya no concentran la mayor parte de las relaciones como ocurría en el primer período, sino que han pasado a formar una agrupación con mayor independencia relacional (figura 7) y temática (figura 8, clúster amarillo). Al definirse mejor esta línea de investigación también se han definido los descriptores relacionados con los estudios sobre las células madre embrionarias (figura 7, zona inferior; figura 8, clúster verde; L.I.3). Si en el primer período estaban muy entremezclados con los estudios de las células madre hematopoyéticas (L.I.2), en este período se definen mejor y además es posible detectar los descriptores relacionados con los procesos de generación de líneas celulares en torno al descriptor Expression (figura 7).

Finalmente los estudios sobre células madre neurales (L.I.4) están mejor definidos tanto temática como estructuralmente. Por tanto se puede señalar la consolidación de esta línea aunque esta última aparece mucho más desarrollada.

La presencia de descriptores de carácter clínico (L.I.1) es más proporcionada al resto de las líneas de investigación, tanto en número como en el peso de sus relaciones. Llama la atención en estos años la distinción (figura 10) de los estudios sobre procesos oncológicos, identificados por el descriptor Bone-Marrow-Transplantation y de los de trasplante de progenitores hematopoyéticos, identificados con el descriptor Stem-Cell Transplantation.

Se identifican 5 agrupaciones de carácter más básico. La primera, mucho mejor definida que en el período anterior, son los estudios sobre células madre hematopoyéticas (figura 10, zona superior izquierda; figura 11, clúster verde; L.I.2), lo que significa su consolidación. Asimismo está conectada con los estudios de uso terapéutico de las células madre
Tabla 6. Datos relativos al tercer período (2007-2010)

\begin{tabular}{|c|c|c|c|}
\hline \multicolumn{4}{|c|}{ Tercer período (2007-2010) } \\
\hline \multirow{2}{*}{ Documentos } & \multicolumn{2}{|l|}{ Totales } & 2.174 \\
\hline & \multicolumn{2}{|c|}{ Indizados con KW+ } & $1.707(78,52 \%)$ \\
\hline \multirow{5}{*}{$K W+$} & \multicolumn{2}{|c|}{ Totales } & 15.521 \\
\hline & \multirow{2}{*}{ Únicos } & Sin normalización & 6.393 \\
\hline & & Con normalización & 6.178 \\
\hline & \multicolumn{2}{|c|}{ Por documento } & 9,1 \\
\hline & \multicolumn{2}{|c|}{ Frecuencia media de aparición } & 2,51 \\
\hline
\end{tabular}


en enfermedades hematooncológicas (L.I.1) y con la investigación en células madre embrionarias (L.I.3). En este período aparecen mejor definidos los estudios sobre procesos de proliferación y diferenciación celular y los relacionados con los procesos y las biotecnologías necesarias para localizar, producir, crecer y sobre todo, analizar in-vitro las células madre embrionarias (figura 10, zona inferior; figura 11 , clúster azul oscuro).

La última línea de investigación (L.I.4) la conforman los estudios relacionados con

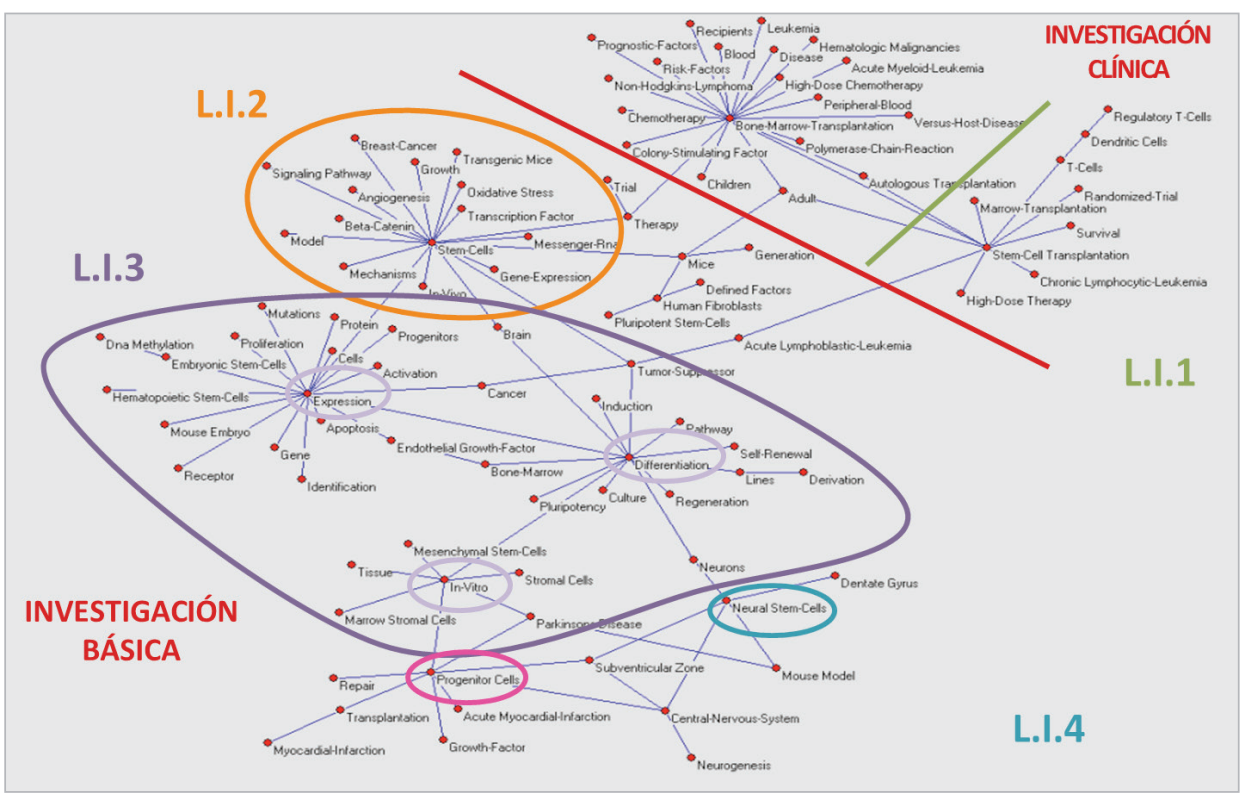

Figura 10. Tercer período (2007-2010). Representación en Pajek de los 98 KW+ más frecuentes.

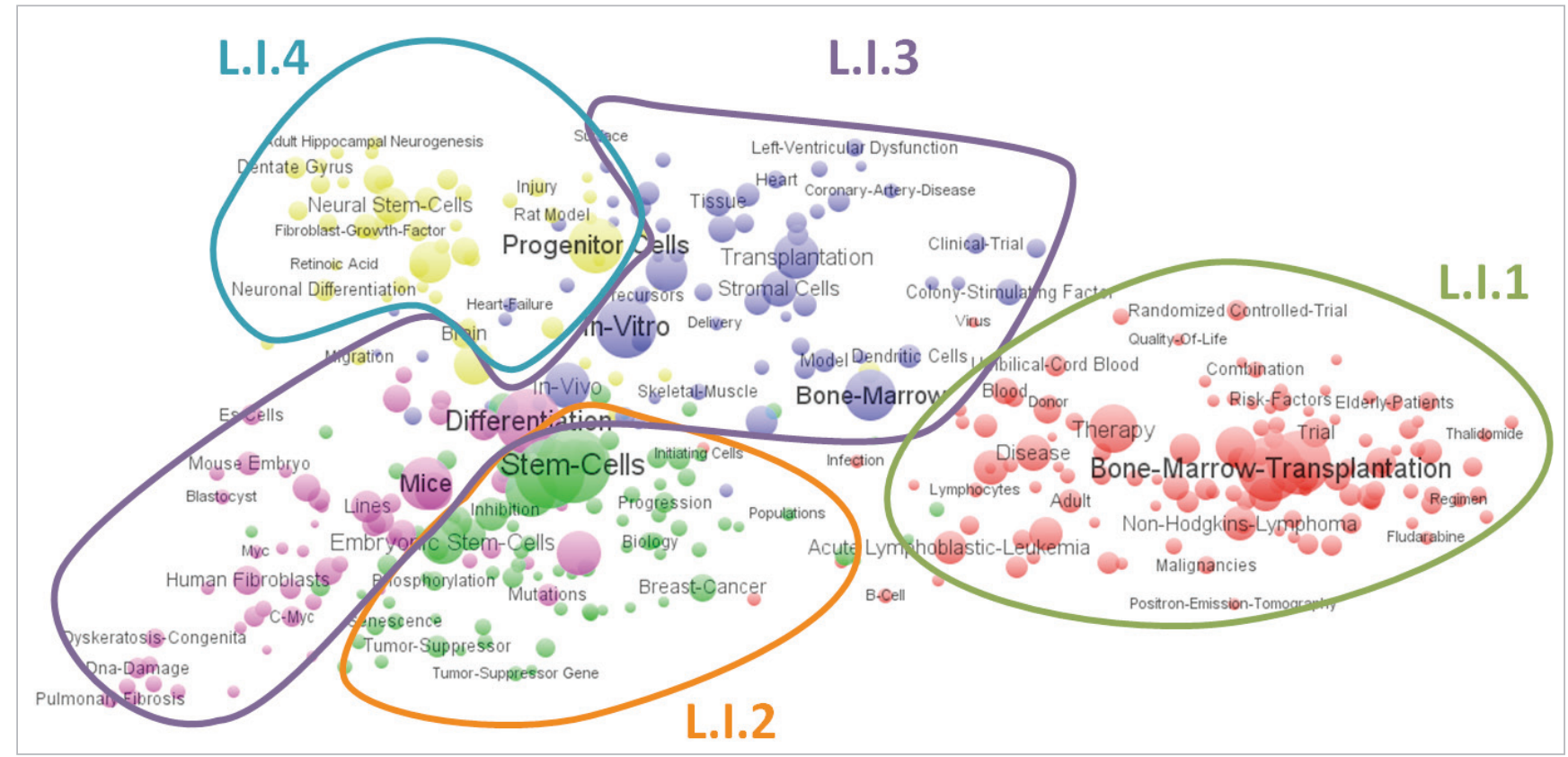

Figura 11. Tercer período (2007-2010). Mapa de clusters representado con VOSviewer (número de nodos: 390).

las células madre neurales (figura 11 , clúster amarillo). En este período los $K W+$ han perdido definición y ya no constituyen un grupo tan homogéneo. Incluso se han desagregado en dos aspectos de la investigación: el desarrollo e identificación de las células madre neurales $y$ el infarto de miocardio empleando progenitores celulares (figura 10). Es posible que esta pérdida de definición se deba a

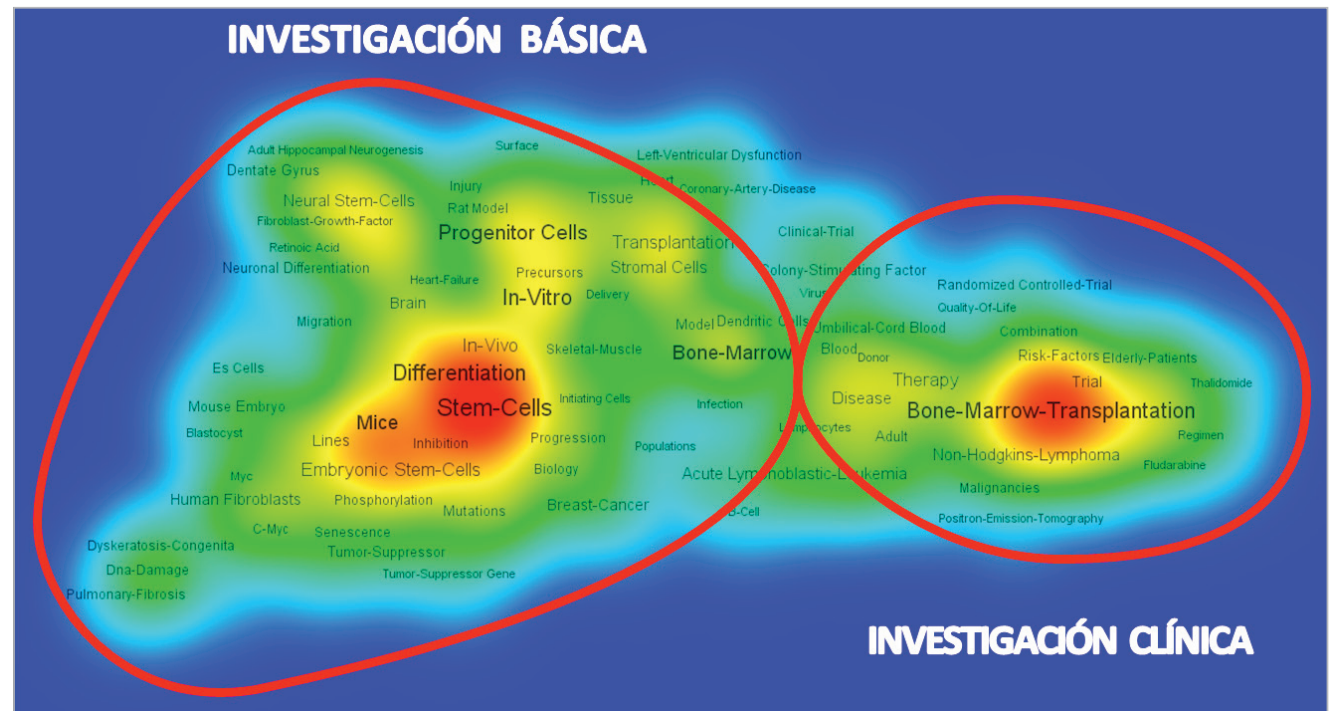

Figura 12. Tercer período (2007-2010). Mapa de calor representado con VOSviewer. 
una nueva línea de investigación emergente que pueda consolidarse con los años.

El estudio del período completo identifica las 4 líneas de investigación más consolidadas: uso terapéutico de células madre en enfermedades hematológicas; células madre hematopoyéticas; embrionarias; y neurales

\section{Conclusiones}

La evolución de la investigación española y su crecimiento están en consonancia con la que se ha llevado a cabo a nivel internacional, tanto en el crecimiento de la literatura a lo largo del período, como su fuerte expansión en el último período analizado. También las líneas de investigación detectadas en las visualizaciones obtenidas en este estudio están relacionadas con la evolución científica internacional, especialmente en la investigación en células madre embrionarias (EuroStemCell et al., 2013).

El estudio del período completo muestra la estructura estática del dominio con la identificación de las 4 líneas de investigación más consolidadas:

- uso terapéutico de células madre en enfermedades oncohematológicas (L.I.1);

- células madre hematopoyéticas (L.I.2);

- células madre embrionarias (L.I.3);

- células madre neuronales (L.I.4).

A través del análisis evolutivo se aprecia cómo se han configurado estas líneas a partir de la consolidación de algunas emergentes y la pérdida de protagonismo de otras. En el primer período hay una fuerte presencia de la hematología y la oncología. El resto de las líneas no comenzaron a detectarse hasta el segundo período con la investigación sobre células madre hematopoyéticas. Finalmente los resultados han mostrado que el peso de estas últimas agrupaciones tuvo una presencia mucho más evidente en el último período, en detrimento de las líneas de investigación relacionadas con la aplicación y la clínica, a diferencia de lo que ocurría en el primer y segundo períodos.

Con estos resultados no es posible concluir que exista una relación directa entre los hitos científicos y normativos acontecidos en España entre los años 1997 y 2010. Sin embargo, parece que las tendencias de investigación están en sintonía con la evolución del marco jurídico-legislativo español y con las principales acciones de incentivación científica en el campo de las células madre. Aunque no es el objeto de estudio, sí parece interesante plantear como estudios futuros un análisis que examine si hay una relación causa-efecto entre los hitos normativos y los científicos.

La propuesta metodológica basada en la visualización de las relaciones entre los $K W+$ ha permitido obtener dos imágenes complementarias de la investigación española sobre cé- lulas madre, proyectando tanto líneas de investigación claramente consolidadas como emergentes. Esto permite intuir metodológicamente la capacidad de predicción de este tipo de estudios en el desarrollo de un dominio temático a lo largo del tiempo. Su aplicabilidad trasciende a otros dominios científicos. La rigidez de las clasificaciones documentales utilizadas por las bases de datos, fundamentalmente de revistas científicas, que proporcionan un nivel de agregación de los dominios científicos excesivamente amplios y poco definidos se vería complementadas por este tipo de análisis al permitir detectar un mayor grado de profundidad de los diferentes dominios científicos.

En cuanto a los programas de visualización utilizados, las imágenes ofrecidas por Pajek y VOSviewer coinciden en las líneas de investigación y en la identificación de los descriptores más influyentes de la red. Además se han complementado bien: Pajek en combinación con PfNET ha permitido sintetizar y resaltar la estructura relacional, mientras que VOSviewer ha hecho posible la identificación de los grupos y focos de investigación de una manera más plástica. Las metodologías de visualización empleadas en este estudio presentan visualizaciones estáticas e independientes de cada período.

\section{Tanto en las visualizaciones del período completo como en la de los sub-perío- dos se distingue claramente la investiga- ción básica y la clínica}

De cara a estudios futuros sería interesante explorar las últimas funciones incorporadas a los dos programas: mapas superpuestos (overlay maps) que permiten fijar la posición de los nodos para hacer estudios evolutivos o comparativos (Rafols; Porter; Leydesdorff, 2010; Leydesdorff; Rafols; Chen, 2013), así como el uso de otros softwares de visualización como Visone utilizado en estudios similares (Leydesdorff et al., 2008; Leydesdorff; Schank, 2008; Baur; Schank, 2008). También sería interesante contrastar esta propuesta metodológica empleando otras unidades de análisis distintas a los $K W+$ con el objetivo de identificar el mejor sistema para definir las líneas de investigación presentes en cada dominio.

\section{Notas}

1. Un avance de los resultados de este trabajo se presentó en el VI Encontro ibérico Edicic 2013; Globalização, ciência, informação, celebrado en Oporto (Portugal), 4-6 nov. 2013.

\section{KeyWords Plus $(K W+)$}

http://interest.science.thomsonreuters.com/content/ WOKUserTips-201010-SEA http://wokinfo.com/media/pdf/qrc/wosqrc.pdf

3. Los Author keywords son el otro tipo que utiliza SCI para indizar los documentos. Éstos se descartaron como unidades de análisis para el estudio, por su baja representatividad a partir de los resultados del estudio que se menciona. 


\section{Agradecimientos}

Este trabajo ha sido posible gracias a la financiación pública obtenida mediante la beca pre doctoral del programa JAEPredoc concedida por el Consejo Superior de Investigaciones Científicas (CSIC) y desarrollada en el Instituto de Políticas y Bienes Públicos (IPP).

\section{Bibliografía}

Batagelj, Vladimir; Mrvar, Andrej (2010). Pajek 2.0: package for large network analysis.

http://vlado.fmf.uni-lj.si/pub/networks/pajek

Baur, Michael; Schank, Thomas (2008). Dynamic graph drawing in visone. Karlsruhe: Technical University Karlsruhe http://i11www.iti.uni-karlsruhe.de/extra/publications/bs$d g d v-08 . p d f$

Börner, Katy; Chen, Chaomei; Boyack, Kevin W. (2003). "Visualizing knowledge domains". Annual review of information science and technology, v. 37, n. 1, pp. 179-255.

http://nwb.cns.iu.edu/papers/arist02.pdf

http://dx.doi.org/10.1002/aris.1440370106

Boyack, Kevin W.; Börner, Katy; Klavans, Richard (2009). "Mapping the structure and evolution of chemistry research". Scientometrics, v. 79, n. 1, pp. 45-60.

http://cns.iu.edu/images/pub/2007-boyack-mapchem.pdf http://dx.doi.org/10.1007/s11192-009-0403-5

Boyack, Kevin W.; Klavans, Richard (2010). "Co-citation analysis, bibliographic coupling, and direct citation: which citation approach represents the research front most accurately?". Journal of the American Society for Information Science and Technology, v. 61, n. 12, pp. 2389-2404.

http://dx.doi.org/10.1002/asi.21419

Braam, Robert R.; Moed, Henk F.; Van-Raan, Anthony F. J. (1991). "Mapping of science by combined co-citation and word analysis. II: Dynamical aspects". Journal of the American Society for Information Science, v. 42, n. 4, pp. 252-266. http://www.cwts.nl/TvR/documents/AvR-CoCit-Word-II.pdf http://dx.doi.org/10.1002/(SICI)1097-4571(199105)42:4\%3C252::AIDASI2\%3E3.0.CO;2-G

Callon, Michell; Courtail, Jean-Pierre; Turner, William A.; Bauin, Serge (1983). "From translations to problematic networks: an introduction to co-word analysis". Social science information sur les sciences sociales, v. 22, n. 2, pp. 191-235. http://dx.doi.org/10.1177/053901883022002003

Cambrosio, Alberto; Limoges, Camille; Courtial, Jean-Pierre; Laville, Françoise (1993). "Historical scientometrics? Mapping over 70 years of biological safety research with coword analysis". Scientometrics, v. 27, n. 2, pp. 119-143. http://dx.doi.org/10.1007/BF02016546

Cantos-Mateos, Gisela; Vargas-Quesada, Benjamín; Chinchilla-Rodríguez, Zaida; Zulueta, María-Ángeles (2012) "Stem cell research: bibliometric analysis of main research areas through KeyWords plus". Aslib proceedings, v. 64, n. 6, pp. 561-590.

http://digital.csic.es/handle/10261/62888?/ocale=es

http://dx.doi.org/10.1108/00012531211281698
Cantos-Mateos, Gisela; Vargas-Quesada, Benjamín; Chinchilla-Rodríguez, Zaida; Zulueta, María-Ángeles (2013). "Estudio comparativo sobre la visualización de redes de cowords a través de los descriptores del Science citation index y Medline". En: I Congresso ISKO Espanha e Portugal / XI Congresso ISKO Espanha, Oporto (Portugal), 7-9 nov. 2013, pp. 173-189.

http://digital.csic.es/handle/10261/89290

http://dx.doi.org/10.1080/00387019808003304

Chen, Chaomei; Ibekwe-SanJuan, Fidelia; Hou, Jianhua (2010). "The structure and dynamics of cocitation clusters: A multiple-perspective cocitation analysis". Journal of the American Society for Information Science and Technology, v. 61, n. 7, pp. 1386-1409.

http://arxiv.org/pdf/1002.1985.pdf

http://dx.doi.org/10.1002/asi.21309

Chen, Dar-Zen; Huang, Mu-Hsuan; Hsieh, Hui-Chen; Lin, Chang-Pin (2011). "Identifying missing relevant patent citation links by using bibliographic coupling in LED illuminating technology". Journal of informetrics, v. 5, n. 3, pp. 400-412. http://dx.doi.org/10.1016/j.joi.2011.02.005

De-Moya-Anegón, Félix; Chinchilla-Rodríguez, Zaida; CoreraÁlvarez, Elena; Gómez-Crisóstomo, Rocío; González-Molina, Antonio; Muñoz-Fernández, Francisco-José; Vargas-Quesada, Benjamín (2007a). Indicadores bibliométricos de la actividad científica española: 1990-2004. Madrid: Fundación Española para la Ciencia y la Tecnología (Fecyt). ISBN: 8469050590 http://eprints.rclis.org/16646

De-Moya-Anegón, Félix; Chinchilla-Rodríguez, Zaida; Corera-Álvarez, Elena; Gómez-Crisóstomo, Rocío; Hassan-Montero, Yusef; Vargas-Quesada, Benjamín (2009). Indicadores bibliométricos de la actividad científica española: 2007. Madrid: Fundación Española para la Ciencia y la Tecnología (Fecyt).

http://icono.fecyt.es/informesypublicaciones/Documents/ indicadores_bibliometricos_2007.pdf

De-Moya-Anegón, Félix; Vargas-Quesada, Benjamín; Chinchilla-Rodríguez, Zaida; Corera-Álvarez, Elena; MuñozFernández, Francisco José; Herrero-Solana, Víctor (2007b). "Visualizing the marrow of science". Journal of the American Society for Information Science and Technology, v. 58, n. 14, pp. 2167-79.

http://digital.csic.es/handle/10261/78646

http://dx.doi.org/10.1002/asi.20683

De-Moya-Anegón, Félix; Vargas-Quesada, Benjamín; Corera-Álvarez, Elena; Muñoz-Fernández, Francisco-José; Herrero-Solana, Víctor; González-Molina, Antonio; Chinchilla-Rodríguez, Zaida (2006). "Visualización y análisis de la estructura científica española: ISI Web of Science 19902005". El profesional de la información, v. 15, n. 4, pp. 258269.

http://eprints.rclis.org/8632

Ding, Ying; Chowdhurry, Gobinda G.; Foo, Schubert (2001). "Bibliometric cartography of information retrieval research by using co-word analysis". Information processing \& management, v. 37, n. 6, pp. 67-78.

http://core.kmi.open.ac.uk/display/9015701 


\section{http://dx.doi.org/10.1016/S0306-4573(00)00051-0}

EuroStemCell, iCeMS, Elsevier (2013). "Stem cell research. Trends and perspectives on the evolving international landscape". http://www.eurostemcell.org/files/Stem-Cell-ReportTrends-and-Perspectives-on-the-Evolving-InternationalLandscape_Dec2013.pdf

Gábor, Csárdi (2006). "Dynamics of citation networks". En: Artificial neural networks - Icann 2006, $16^{\text {th }}$ Int I conf, Athens, Greece, Sept. 10-14, pp. 698-709.

Garfield, Eugene (1990). “Keywords Plus-ISI's breakthrough retrieval method. Part 1. Expanding your searching power on Current contents on diskette". Current contents, v. I, n. 32, pp. 5-9.

http://www.garfield.library.upenn.edu/essays/ v13p295y1990.pdf

http://dx.doi.org/10.1007/s00338-008-0431-2

Garfield, Eugene; Sher, Irving H. (1993). "Keywords PlusTM - Algorithmic derivative indexing". Journal of the American Society for Information Science, v. 44, n. 5, pp. 298-299.

http://www.garfield.library.upenn.edu/papers/jasis44(5) p298y1993.html

http://dx.doi.org/10.1002/(SICl)1097-4571(199306)44:5\%3C298::AIDASI5\%3E3.0.CO;2-A

Glänzel, Wolfgang; Thijs, Bart (2011). "Using 'core documents' for the representation of clusters and topics". Scientometrics, July, v. 88, n. 1, pp. 297-309.

http://dx.doi.org/10.1007/s11192-011-0347-4

Hammond, John (1949). "Recovery and culture of tubal mouse ova". Nature, v. 163, n. 4131, pp. 28-29.

http://dx.doi.org/10.1038/163028b0

Kamada, Tomihisa; Kawai, Satoru (1989). “An algorithm for drawing general undirected graphs". Information procesing letters, v. 31, n. 1, April, pp. 7-15.

http://dx.doi.org/10.1016/0020-0190(89)90102-6

Kessler, Meyer-Mike (1963). "Bibliographic coupling between scientific papers". American documentation, v. 14, n. 1, pp. 10-25.

http://dx.doi.org/10.1002/asi.5090140103

Lee, Woo-Hyoung (2008). "How to identify emerging research fields using scientometrics: an example in the field of information security". Scientometrics, v. 76, n. 3, pp. 503-525. http://dx.doi.org/10.1007/s11192-007-1898-2

Leydesdorff, Loet; Rafols, Ismael (2009). "A global map of science based on the ISI subject categories". Journal of the American Society for Information Science and Technology, v. 60, n. 2, pp. 348-362.

http://arxiv.org/pdf/0911.1057.pdf

http://dx.doi.org/10.1002/asi.20967

Leydesdorff, Loet; Rafols, Ismael; Chen, Chaomei (2013). "Interactive overlays of journals and the measurement of interdisciplinarity on the basis of aggregated journal-journal citations". Journal of the American Society for Information Science and Technology, v. 64, n. 12, pp. 2573-2586.

http://arxiv.org/pdf/1301.1013.pdf

http://dx.doi.org/10.1002/asi.22946
Leydesdorff, Loet; Schank, Thomas (2008) “Dynamic animations of journal maps: indicators of structural change and interdisciplinary developments". Journal of the American Society for Information Science and Technology, v. 59, n. 11, pp. 1810-1818.

http://arxiv.org/pdf/0911.1437v1.pdf

Leydesdorff, Loet; Schank, Thomas; Scharnhorst, Andrea; De Nooy, Wouter (2008). "Animating the development of social networks over time using a dynamic extension of multidimensional scaling". El profesional de la información, nov.-dic., v. 17 , n. 6 , pp. 611-626.

http://www.elprofesionaldelainformacion.com/ contenidos/2008/noviembre/04.pdf

http://dx.doi.org/10.3145/epi.2008.nov.04

Leydesdorff, Loet; Welbers, Kasper (2011). "The semantic mapping of words and co-words in contexts". Journal of informetrics, July, v. 5, n. 3, pp. 469-475.

http://arxiv.org/pdf/1011.5209v2.pdf

http://dx.doi.org/10.1016/j.joi.2011.01.008

Rafols, Ismael; Porter, Alan L.; Leydesdorff, Loet (2010). "Science overlay maps: a new tool for research policy and library management". Journal of the American Society for Information Science and Technology, v. 61, n. 9, pp. 18711887.

http://www.leydesdorff.net/overlaytoolkit/overlaytoolkit.pdf http://dx.doi.org/10.1002/asi.21368

Rip, Arie; Courtial, Jean-Pierre (1984). "Co-word maps of biotechnology: An example of cognitive scientometrics". Scientometrics, v. 6, n. 6, pp. 381-400.

http://doc.utwente.nl/57102/1/co-word.pdf

http://dx.doi.org/10.1007/BF02025827

Romo-Fernández, Luz M.; Guerrero-Bote, Vicente P.; DeMoya-Anegón, Félix (2013). "Co-word based thematic analysis of renewable energy (1990-2010)". Scientometrics, v. 97, n. 3, pp. 743-765.

http://dx.doi.org/10.1007/s11192-013-1009-5

Small, Henry; Upham, Phineas (2009). "Citation structure of an emerging research area on the verge of application". Scientometrics, v. 79, n. 2, pp.365-375.

http://dx.doi.org/10.1007/s11192-009-0424-0

Soos, Sandor; Kampis, George; Gulyás, László (2013). “Large-scale temporal analysis of computer and information science". The European physical journal special topics, v. 222, n. 6, pp. 1441-1465.

http://dx.doi.org/10.1140/epjst/e2013-01936-6

Takahashi, Kazutoshi; Tanabe, Koji; Ohnuki, Mari; Narita, Megumi; Ichisaka, Tomoko; Tomoda, Kiichiro; Yamanaka, Shinya (2007). "Induction of pluripotent stem cells from adult human fibroblasts by defined factors". Cell, v. $131 \mathrm{n}$. 5, pp. 861-872.

http://images.cell.com/images/Edimages/Cell/IEPs/3661.pdf http://dx.doi.org/10.1016/j.cell.2007.11.019

Takahashi, Kazutoshi; Yamanaka, Shinya (2006). "Induction of pluripotent stem cells from mouse embryonic and adult fibroblast cultures by defined factors". Cell, v. 126, n. 4, pp. 663-676. http://www.cell.com/cell/fulltext/s0092-8674(06)00976-7 
http://dx.doi.org/10.1016/j.cell.2006.07.024

Van-Eck, Nees-Jan; Waltman, Ludo (2010). "Software survey: VOSviewer, a computer program for bibliometric mapping". Scientometrics, v. 84, n. 2, pp. 523-38.

http://www.ncbi.nlm.nih.gov/pmc/articles/PMC2883932

http://dx.doi.org/10.1007/s11192-009-0146-3

Van-Raan, Anthony F. J.; Tijssen, Robert J. W. (1993). "The neural net of neural network research. An exercise in bibliometric mapping". Scientometrics, v. 26, n. 1, pp. 169-192.

http://dx.doi.org/10.1007/BF02016799

Vargas-Quesada, Benjamín; Chinchilla-Rodríguez, Zaida; González-Molina, Antonio; De-Moya-Anegón, Félix (2010). "Showing the essential science structure of a scientific domain and its evolution". Information visualization, v. 9, n. 4, pp. 288-300.

http://www.ugr.es/ benjamin/showing.pdf

http://dx.doi.org/10.1057/ivs.2009.33

Vargas-Quesada, Benjamín; De-Moya-Anegón, Félix; Chinchilla-Rodríguez, Zaida; Corera-Álvarez, Elena; GuerreroBote, Vicente (2008). "Development of the Spanish scientific landscape: ISI Web of science 1990-2005". El profesional de la informacion, v. 17, n. 1, pp. 22-37.

http://eprints.rclis.org/16683/1/evolucion_estructura_ cientifica_espa\%C3\%B1ola.pdf

http://dx.doi.org/10.3145/epi.2008.ene.03

Wasserman, Stanley; Faust, Katherine (1998). Social network analysis: methods and applications. Cambridge: Cambridge University Press. ISBN: 9780511815478.

http://dx.doi.org/10.1017/CBO9780511815478

White, Howard D. (2003). "Pathfinder networks and author co-citation analysis: a remapping of paradigmatic information scientists". Journal of the American Society for Information Science and Technology, v. 54, n. 5, pp. 423-34. http://dx.doi.org/10.1002/asi.10228

White, Howard D.; Griffith, Belver C. (1981). "Author cocitation: a literature measure of intellectual structure". Journal of the American Society for Information Science, mayo, v. 32 , n. 3 , pp. $163-171$.

http://dx.doi.org/10.1002/asi.4630320302

White, Howard D.; McCain, Katherine W. (1998). "Visualizing a discipline: an author co-citation analysis of information science, 1972-1995". Journal of the American Society for Information Science, v. 49, n. 4, pp. 327-375.

http://comminfo.rutgers.edu/ kantor/601/Readings2004/ Week2/w2r2.PDF

http://dx.doi.org/10.1002/(SICI)1097-4571(19980401)49:4\%3C327::AIDASI4\%3E3.0.CO;2-4

Wilmut, Ian; Schnieke, Angelika E.; McWhir, Jim; Kind, Alexander J.; Campbell, Keith H. S. (1997). "Viable offspring derived from fetal and adult mammalian cells". Nature, v. 385, n. 6619, pp. 810-813.

http://dx.doi.org/10.1038/385810a0

Zhao, Dangzhi; Strotmann, Andreas (2011). "Intellectual structure of stem cell research: a comprehensive author cocitation analysis of a highly collaborative and multidisciplinary field". Scientometrics, v. 87, n. 1, pp. 15-131. http://dx.doi.org/10.1007/s11192-010-0317-2

Zitt, Michel; Bassecoulard, Elise (1996). "Reassessment of co-citation methods for science indicators: effect of methods improving recall rates". Scientometrics, v. 37, n. 2, pp. 223-244.

http://dx.doi.org/10.1007/BF02093622

Zitt, Michel; Lelu, Alain; Bassecoulard, Elise (2011). "Hybrid citation-word representations in science mapping: Portolan charts or research fields?" Journal of the American Society for Information Science and Technology, v. 62, n. 1, pp. 19-39. http://dx.doi.org/10.1002/asi.21440

Zulueta, María-Ángeles; Cantos-Mateos, Gisela; Sánchez, Carmen; Vargas-Quesada, Benjamín (2011). "Research involving women and health in the Medline database, 19652005. Co-term analysis and visualization of main lines of research". Scientometrics, v. 88, n. 3, pp. 679-706. http://dx.doi.org/10.1007/s11192-011-0455-1

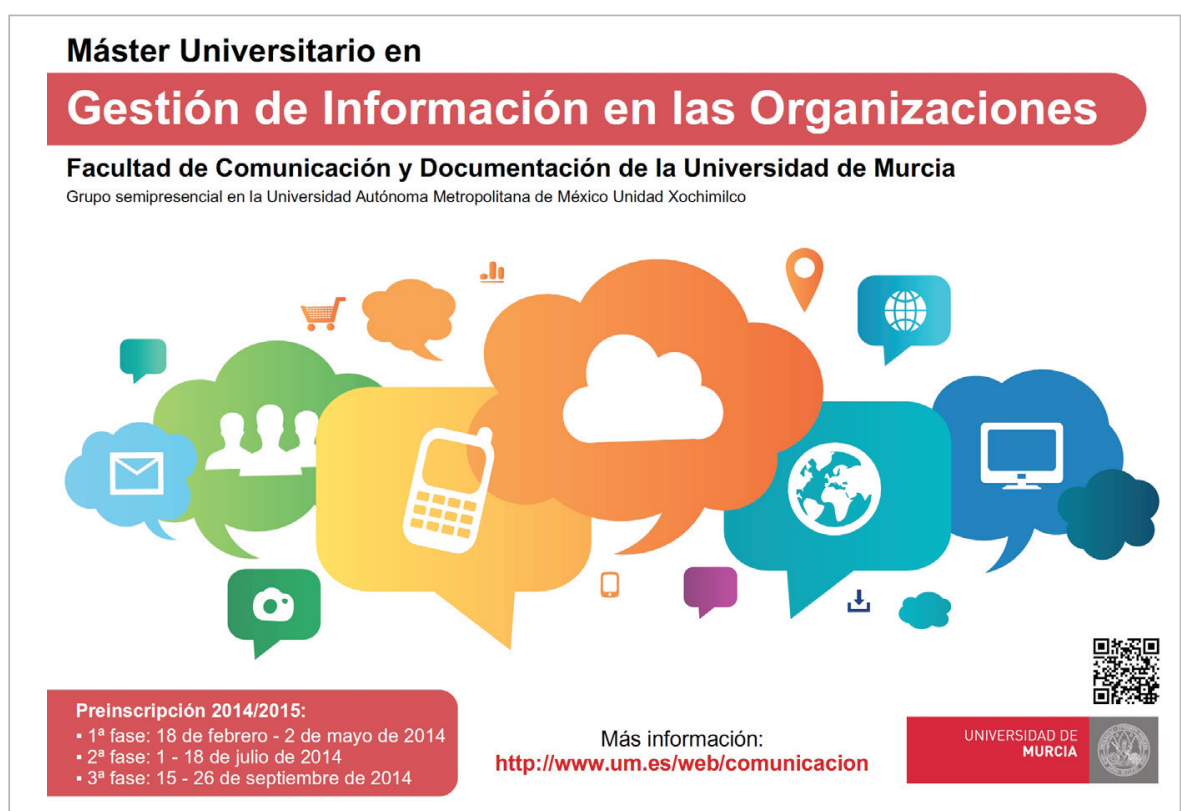

